\title{
Quantitation of microRNAs using a modified Invader assay
}

\author{
HATIM T. ALLAWI, ${ }^{1}$ JAMES E. DAHLBERG, ${ }^{2}$ SARAH OLSON, ${ }^{1}$ ELSEBET LUND, ${ }^{2}$ MARILYN OLSON, ${ }^{1}$ \\ WU-PO MA, ${ }^{1}$ TSETSKA TAKOVA, ${ }^{1}$ BRUCE P. NERI, ${ }^{1}$ and VICTOR I. LYAMICHEV ${ }^{\mathbf{1}}$ \\ ${ }^{1}$ Third Wave Technologies, Inc., Madison, Wisconsin 53719, USA \\ ${ }^{2}$ Department of Biomolecular Chemistry, University of Wisconsin Medical School, Madison, Wisconsin 53706, USA
}

\begin{abstract}
The short lengths of microRNAs (miRNAs) present a significant challenge for detection and quantitation using conventional methods for RNA analysis. To address this problem, we developed a quantitative, sensitive, and rapid miRNA assay based on our previously described messenger RNA Invader assay. This assay was used successfully in the analysis of several miRNAs, using as little as 50-100 ng of total cellular RNA or as few as 1,000 lysed cells. Its specificity allowed for discrimination between miRNAs differing by a single nucleotide, and between precursor and mature miRNAs. The Invader miRNA assay, which can be performed in unfractionated detergent lysates, uses fluorescence detection in microtiter plates and requires only 2-3 h incubation time, allowing for parallel analysis of multiple samples in high-throughput screening analyses.
\end{abstract}

Keywords: miRNA; siRNA; RNAi; structure-specific 5'-nuclease; 2'-O-methyl; Invader assay; cell lysates

\section{INTRODUCTION}

MicroRNAs (miRNAs) and small interfering RNAs (siRNAs; Lagos-Quintana et al. 2001; Lau et al. 2001; Lee and Ambros 2001; Mourelatos et al. 2002; Reinhart et al. 2002) can regulate the translation and stability of messenger RNAs (mRNAs) in higher eukaryotes (Lee et al. 1993; Banerjee and Slack 2002; Carmell et al. 2002; Moss and Poethig 2002; Pasquinelli and Ruvkun 2002; Carrington and Ambros 2003; Dykxhoorn et al. 2003; Kidner and Martienssen 2003; Krichevsky et al. 2003; Bartel 2004). In addition to their impact on normal gene expression, these small ( $\sim 22$ nucleotides) RNAs have great potential in areas of therapeutics and drug discovery. Our understanding of these RNAs would be facilitated by development of new methods to study them. For example, several nonidentical but closely related miRNAs have been described that are not easily distinguishable by available methods although they may differ in their targets or activities. Also, some important, biologically active endogenous or introduced miRNAs or siRNAs may be present at levels that are too low to be detected or quantified directly (Kim et al. 2004; Sempere et al. 2004). To date, the principal methods used for detection and quantification of miRNAs are based on sequencing, gel electrophoresis, and hybridization.

Reprint requests to: Hatim T. Allawi, Third Wave Technologies, Inc., 502 South Rosa Rd., Madison, WI 53719, USA; e-mail: hallawi@twt.com; fax: (608) 273-8618.

Article and publication are at http://www.rnajournal.org/cgi/doi/ 10.1261/rna.5250604.
Here, we describe a method, which we call the Invader miRNA assay, for the sensitive and specific detection and quantitation of miRNAs or siRNAs. It is based on a similar method that we previously developed to detect mRNAs, the Invader mRNA assay (Eis et al. 2001; de Arruda et al. 2002). The Invader miRNA assay has the ability to detect and quantitate as few as 20,000 molecules of an individual miRNA. It distinguishes between miRNAs and their precursors, as well as between closely related miRNA isotypes. The assay is rapid and can be performed in detergent lysates of cells.

\section{RESULTS AND DISCUSSION}

The Invader assay (Fig. 1) is based on enzymatic cleavage by a structure-specific $5^{\prime}$ nuclease (Cleavase) of a synthetic oligonucleotide (the probe) that is in an appropriate overlap-flap structure (Kaiser et al. 1999). The structure is generated by hybridization of a target nucleic acid to two deoxy-oligonucleotides, called the probe and invasive oligonucleotides, in a partially overlapping manner (Fig. 1A; Lyamichev et al. 1999; Hall et al. 2000). The specificity of the assay results from the ability of the enzyme to detect base pairing of the probe at the site of substrate cleavage. The released $5^{\prime}$ flap fragment is detected in the same reaction tube, when it serves as an invasive oligonucleotide in a second cleavage reaction (Fig. 1B). The substrate of this secondary reaction is an oligonucleotide containing a fluorescent dye $(\mathrm{F})$ and a quencher $(\mathrm{Q})$, which form a fluorescence resonance energy transfer (FRET) pair that is sepa- 
A

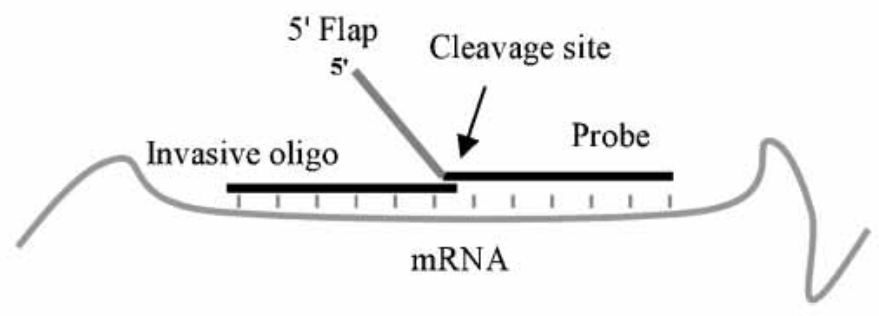

B

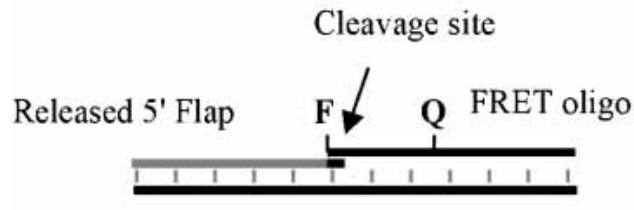

Secondary Reaction Template (SRT)

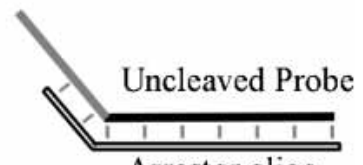

Arrestor oligo

C

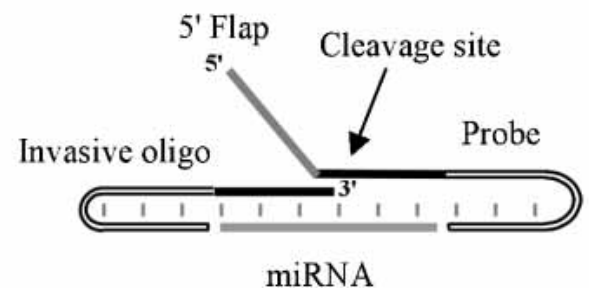

FIGURE 1. Schematic representation of the Invader miRNA assay. (A) Primary reaction of the Invader mRNA assay: Annealing of the invasive and probe oligonucleotides to an RNA target forms an overlap-flap structure that is a substrate for the structure-specific $5^{\prime}$ nuclease, Cleavase. The mRNA target is shown in gray and the target-specific oligonucleotides are shown in black. The noncomplementary $5^{\prime}$ flap of the probe oligonucleotide is hatched, and the arrow indicates the site of cleavage, which releases the $5^{\prime}$ flap. (B) Secondary reaction to generate quantifiable signals: A secondary overlap-flap structure is formed by hybridizing both the $5^{\prime}$ flap that had been released in the primary reaction and a FRET oligonucleotide to a secondary reaction template (SRT). The FRET oligonucleotide is labeled with a fluorophore (F) and a quencher $(\mathrm{Q})$ so cleavage between them generates a fluorescence signal. A 2'-O-methyl arrestor oligonucleotide (double lines) complementary to the probe is added to the secondary reaction, to sequester the uncleaved probes so they cannot bind to the SRT. (C) Invader miRNA assay primary reaction: The overall structure of the substrate resembles that shown in $A$, except that the short size of the miRNA target requires the inclusion of extra structures derived from the invasive and probe oligonucleotides, forming a dumbbell-like structure. The miRNA target is shown in gray, the target-specific oligonucleotide sequences in black, and the stem-loop hairpin regions of the invasive and probe oligonucleotides, which contain 2'-O-methyl nucleotides, are shown by double lines. The noncomplementary $5^{\prime}$-flap is hatched and the arrow indicates the site of cleavage, which releases the $5^{\prime}$ flap.

rated upon cleavage. Background is kept low by addition of an oligonucleotide (the Arrestor) that hybridizes to uncleaved probe and keeps it from participating in the sec-

ondary reaction. Thus, a simple fluorometric assay indicates the amount of target nucleic acid present in a sample, based on the number of flap structures that formed on the target nucleic acid.

The invasive and probe oligonucleotides for the Invader miRNA assay are designed so that each one base pairs with about half of the nucleotides of the miRNA (Fig. 1C). Stability of the interaction is increased by inclusion of stemloops at the $5^{\prime}$ and $3^{\prime}$ ends of the invasive and probe oligonucleotides, respectively, to promote base stacking with the short, targeted RNA. Release of the probe from the target is promoted by performing the cleavage reactions at elevated temperatures, resulting in very high turnover, and hence sensitivity, of the assay (Lyamichev et al. 2000). The enzyme preferentially stabilizes interaction between the invasive oligonucleotide and the target (data not shown), allowing for multiple probe cleavages in response to a single target RNA.

When a set of oligonucleotides designed to detect let-7a RNA (Fig. 2A) was incubated with synthetic let-7a RNA, a fluorescence signal was generated, showing that the assay can detect miRNAs (Fig. 2B). The signal increased in proportion to the amount of RNA, over three orders of magnitude, and was detectable even when only $\sim 20,000$ molecules of target miRNA were present in the reaction. Thus, the assay is able to detect miRNAs that might be present at very low levels.

The specificity of the Invader miRNA assay was investigated at several temperatures, using closely related variants of let-7 RNA that differed from it by only 1 of $22 \mathrm{nt}$ (Fig. 2A). Addition of let-7a RNA resulted in much greater signal than did addition of the variant RNAs (Fig. 2C). Conversely, an assay that was designed to detect let-7c RNA generated significant signal in the presence of let-7c RNA but not the other let-7 variants or let-7a RNA (Fig. 2D,E). Thus, the method is able to discriminate between miRNAs that differ in sequence by less than $5 \%$. The magnitude of discrimination was greatest when the sequence differences were near the middle of the miRNA, opposite the site of cleavage. We propose 
A

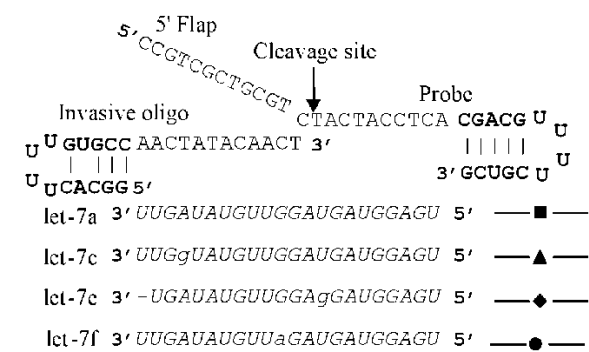

B

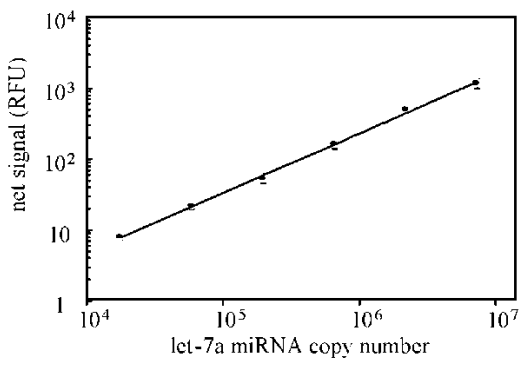

$\mathrm{C}$

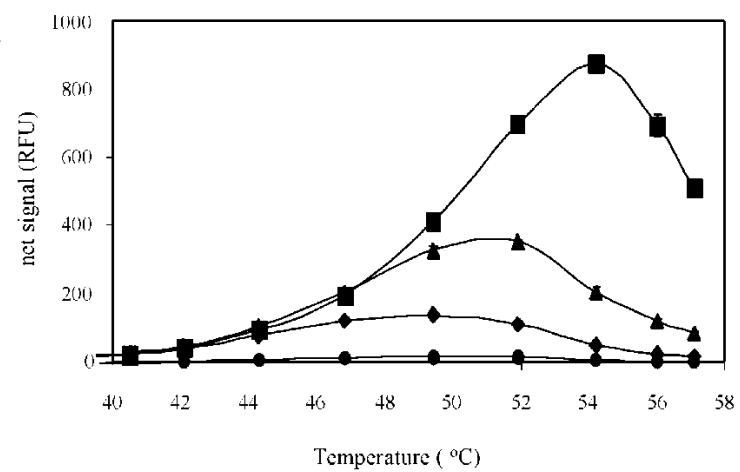

$\mathrm{D}$

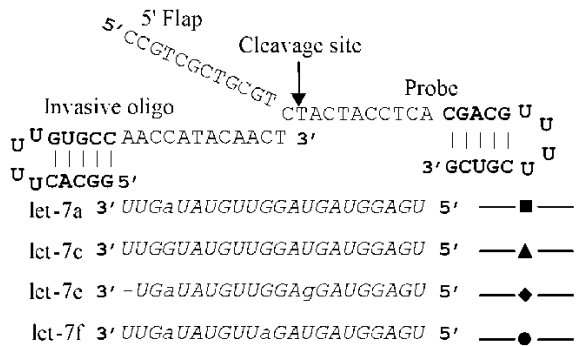

$\mathrm{E}$

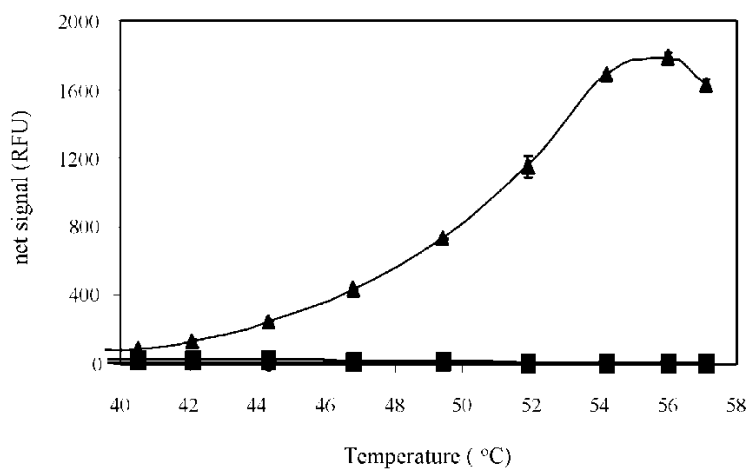

FIGURE 2. (A) Invasive and probe oligonucleotides designed to detect let-7a RNA, and nucleotide sequences of let-7a RNA and closely related let-7 variants (shown in italics); nucleotide differences from let-7a RNA are in lowercase or a dash. 2'-O-methyl containing nucleotides of the regions forming hairpin structures are in bold. $(B)$ Dose response of the net fluorescence signal generated in the Invader assay using synthetic let-7a RNA. (C) Temperature dependence of the fluorescence signals generated in the Invader miRNA assay using as targets the let-7 variants indicated in $A$. $(D)$ Invasive and probe oligonucleotides designed to detect let-7c RNA, and nucleotide sequences of let-7 variants highlighted (in lowercase or by a dash) where the sequence differs from let-7c. (E) Temperature dependence of the fluorescence signals generated in the Invader let-7c assay using as targets the let-7 variants indicated in $D$. let-7a, let-7e, and let-7f variants generated very low net signal and their temperaturedependence curves are superimposed in the figure.

that the let-7c assay is more discriminating than the let-7a assay (Fig. 2, cf. C and E) because of the relative stabilities of the mismatched nucleotides (A-C vs. G-T).

We tested the importance of hairpins at the ends of the probe and invasive oligonucleotides by comparing the signals generated when the hairpins were or were not present. In almost all of the Invader miRNA assays both hairpins are needed for efficient detection. Curiously, however, omission of the hairpin from the probe oligonucleotide used to detect let-7a RNA appeared to increase its ability to detect very low amounts of let-7a RNA, concomitant with a slight reduction in the optimal temperature of assay (data not shown); this increased sensitivity may be due to better product release. The assays for other miRNAs appeared to be more dependent on the $3^{\prime}$ hairpin, so in all assays described below, with the exception of those for let-7a RNA, both the probe and invasive oligonucleotides had hairpins, as illustrated in Figures 1C and 2A and Table 1.

When a precursor of let-7a RNA was used instead of the mature miRNA, the signal was reduced by more than $95 \%$ (not shown), demonstrating that the assay can differentiate between mature and precursor forms of miRNAs. That is likely because of competition between the oligonucleotides used in the assay and the region of the precursor that is highly complementary to let-7a RNA. Every pre-miRNA described to date contains a sequence that is partially complementary to its embedded miRNA, allowing for formation of an imperfect duplex needed in the processing of pre-miRNAs by Dicer (Bartel 2004). Thus it is unlikely that any pre-miRNA will generate a signal in this assay.

The presence of an extra, overlapping nucleotide at each end of the RNA heteroduplex reduced the maximum signal 
Allawi et al.

TABLE 1. Oligonucleotide sequences used for microRNA detection using the Invader assay

\begin{tabular}{|c|c|c|c|}
\hline Assay & $\begin{array}{c}\text { Oligonucleotide } \\
\text { description }\end{array}$ & Oligonucleotide sequence $\left(5^{\prime} \rightarrow 3^{\prime}\right)$ & $\begin{array}{c}\text { Optimal assay } \\
\text { temperature }\end{array}$ \\
\hline let-7a & $\begin{array}{l}\text { synthetic RNA target } \\
\text { probe } \\
\text { invader } \\
\text { arrestor }\end{array}$ & $\begin{array}{l}\text { ugagguaguagguuguauaguu } \\
\text { CCGTCGCTGCGTCTACTACCTCACGAGUUUUCGUCG } \\
\text { GGCACUUUUGUGCCAACTATACAACT } \\
\text { UGAGGUAGUAGACGCAG }\end{array}$ & $54^{\circ} \mathrm{C}^{\mathrm{a}}$ \\
\hline let-7c & $\begin{array}{l}\text { synthetic RNA target } \\
\text { probe } \\
\text { invader } \\
\text { arrestor }\end{array}$ & $\begin{array}{l}\text { ugagguaguagguuguaugguu } \\
\text { CCGTCGCTGCGTCTACTACCTCACGAGUUUUCGUCG } \\
\text { GGCACUUUUGUGCCAACCATACAACT } \\
\text { UGAGGUAGUAGACGCAG }\end{array}$ & $54^{\circ} \mathrm{C}$ \\
\hline miR-1 & $\begin{array}{l}\text { synthetic RNA targt } \\
\text { probe } \\
\text { invader } \\
\text { arrestor }\end{array}$ & $\begin{array}{l}\text { uggaauguaaagaaguauggag } \\
\text { AACGAGGCGCACTTTACATTCCACGAGCCUUUUGGCUCG } \\
\text { GGCAGCUUUUGCUGCCCTCCATACTTCC } \\
\underline{\text { UGGAAUGUAAAGUGCGC }}\end{array}$ & $50^{\circ} \mathrm{C}$ \\
\hline $\operatorname{miR}-15$ & $\begin{array}{l}\text { synthetic RNA target } \\
\text { probe } \\
\text { invader } \\
\text { arrestor }\end{array}$ & $\begin{array}{l}\text { uagcagcacauaaugguuugug } \\
\text { AACGAGGCGCACATGTGCTGCTACGAGCCUUUUGGCUCG } \\
\text { GGCAGCUUUUGCUGCCCACAAACCATTC } \\
\underline{\text { UAGCAGCACAUGUGCGC }}\end{array}$ & $53^{\circ} \mathrm{C}$ \\
\hline miR-16 & $\begin{array}{l}\text { synthetic RNA target } \\
\text { probe } \\
\text { invader } \\
\text { arrestor }\end{array}$ & $\begin{array}{l}\text { uagcagcacguaaauauuggcg } \\
\text { AACGAGGCGCACTACGTGCTGCTACGAGCCUUUUGGCUCG } \\
\text { GGCAGCUUUUGCUGCCCGCCAATATTG } \\
\underline{\text { UAGCAGCACGUAGUGCGC }}\end{array}$ & $56^{\circ} \mathrm{C}$ \\
\hline $\operatorname{miR}-125 b$ & $\begin{array}{l}\text { synthetic RNA target } \\
\text { probe } \\
\text { invader } \\
\text { arrestor }\end{array}$ & $\begin{array}{l}\text { ucccugagacccuaacuuguga } \\
\text { AACGAGGCGCACGGTCTCAGGGACGAGCCUUUUGGCUCG } \\
\text { GGCAGCUUUUGCUGCCTCACAAGTTAGA } \\
\underline{\text { UCCCUGAGACCGUGCGC }}\end{array}$ & $52^{\circ} \mathrm{C}$ \\
\hline miR-135 & $\begin{array}{l}\text { synthetic RNA target } \\
\text { probe } \\
\text { invader } \\
\text { arrestor }\end{array}$ & $\begin{array}{l}\text { uauggcuuuuuauuccuaugugaa } \\
\text { AACGAGGCGCACAATAAAAAGCCATACGAGCCGAAAGGCUCG } \\
\text { CCGAGCGAAAGCUCGGTTCACATAGGC } \\
\text { UAUGGCUUUUUAUUGUGCGC }\end{array}$ & $45^{\circ} \mathrm{C}$ \\
\hline U6 snRNA & $\begin{array}{l}\text { synthetic RNA target } \\
\text { probe } \\
\text { invader } \\
\text { arrestor }\end{array}$ & $\begin{array}{l}\text { auacagagaagauuagcauggccccugcgcaaggaug } \\
\text { CCGCCGAGATCACCTAATCTTCTCTGTAT } \\
\text { CATCCTTGCGCAGGGGCCATGA } \\
\text { AUACAGAGAAGAUUAGGUGAUC } \\
\end{array}$ & $51^{\circ} \mathrm{C}^{\mathrm{b}}$ \\
\hline \multicolumn{2}{|c|}{ FAM FRET probe } & Fam-CAC-Q-TGCTTCGTGG & \\
\hline \multicolumn{2}{|c|}{ RED FRET probe } & Red-CTC-Q-TTTCTCAGTGCG & \\
\hline \multicolumn{2}{|c|}{ FAM specific secondary reaction template 1} & CCAGGCAGCAAGTGGTGCGCCTCGTTT & \\
\hline \multicolumn{2}{|c|}{ FAM specific secondary reaction template 2} & CCAGGAAGCAAGTGACGCAGCGACGGT & \\
\hline \multicolumn{2}{|c|}{ RED specific secondary reaction template 1} & CGCAGTGAGAATGAGGTGATCTCGGCGGT & \\
\hline
\end{tabular}

by about $50 \%$ (data not shown). Similarly, a single nucleotide gap at one or both ends of the miRNA reduced the optimal temperature by several degrees and also reduced the signal (data not shown). The presence or absence of a $5^{\prime}$ phosphate on the miRNA was without effect on the performance of the assay. Thus, base stacking between the ends of the miRNA and the invasive and probe oligonucleotides appears to be important, but not essential for detection. We have not undertaken a detailed analysis of the sensitivity of the assay to heterogeneities in the lengths of miRNAs.
The assay detected let-7a RNA in as little as 50-100 ng of unfractionated total RNA prepared from human tissues (Fig. 3A). Because the signal generated was proportional to the amount of let-7a RNA in the sample, we were able to estimate the relative amounts of this RNA in a fixed amount of tissue RNA. For the sake of comparison, the data were normalized to the level in whole brain (Fig. 3A). The results show that the amounts of let-7a RNA per cell vary over several orders of magnitude between tissues, as previously reported by Pasquinelli et al. (2000). Assuming that each 
A

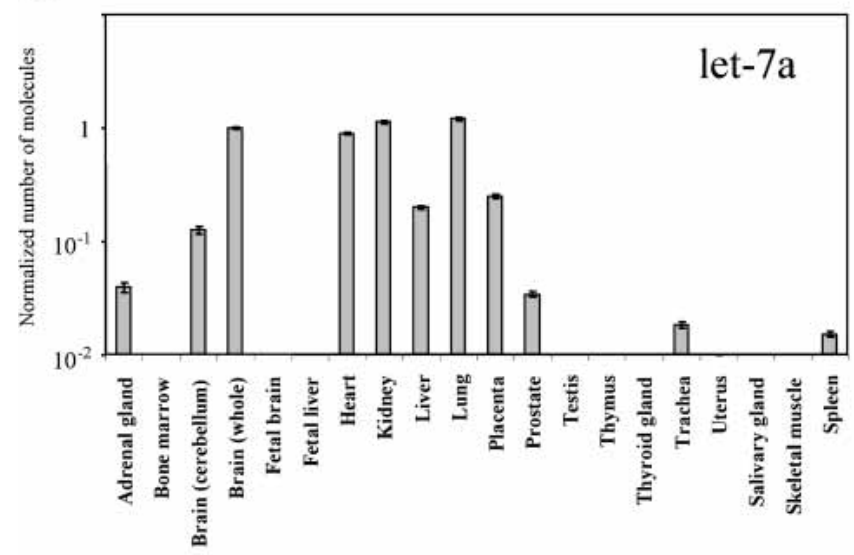

B

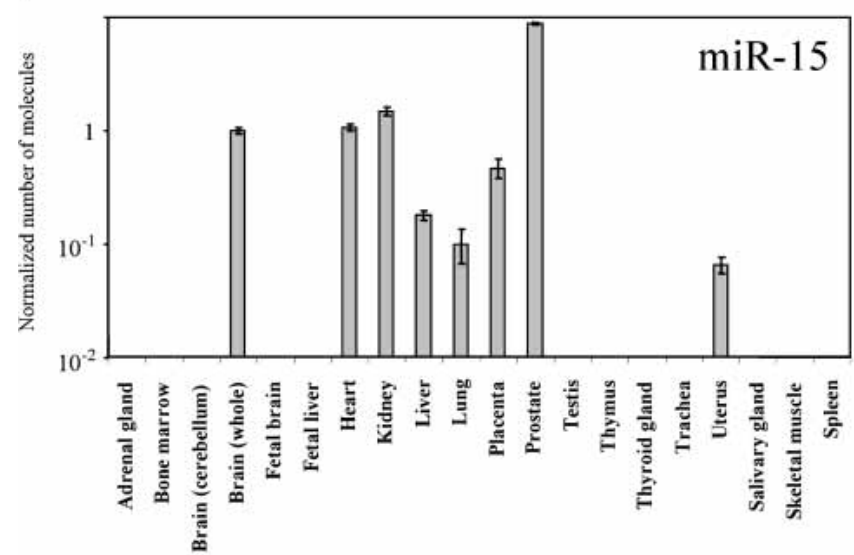

$\mathrm{C}$

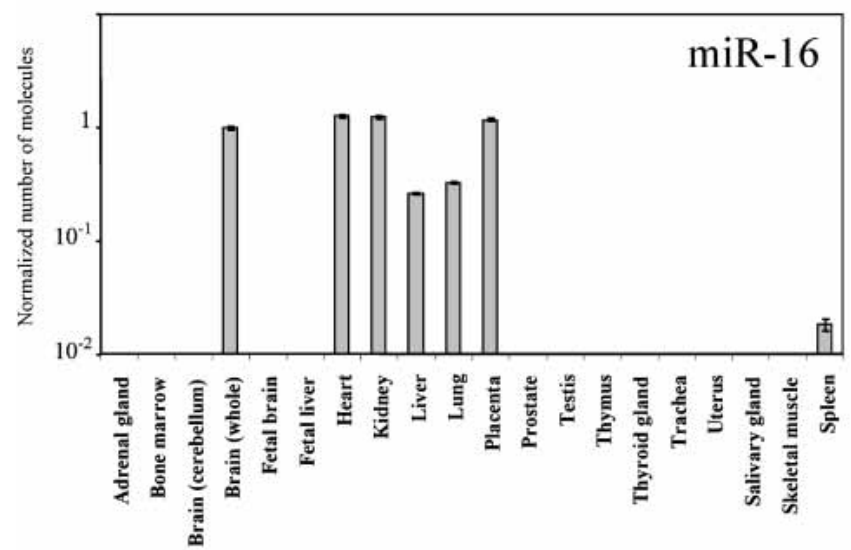

$\mathrm{D}$

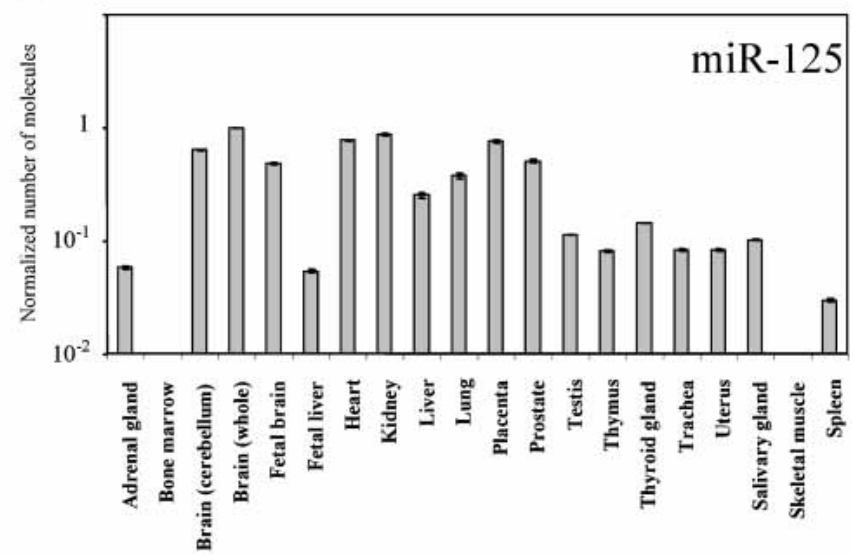

E

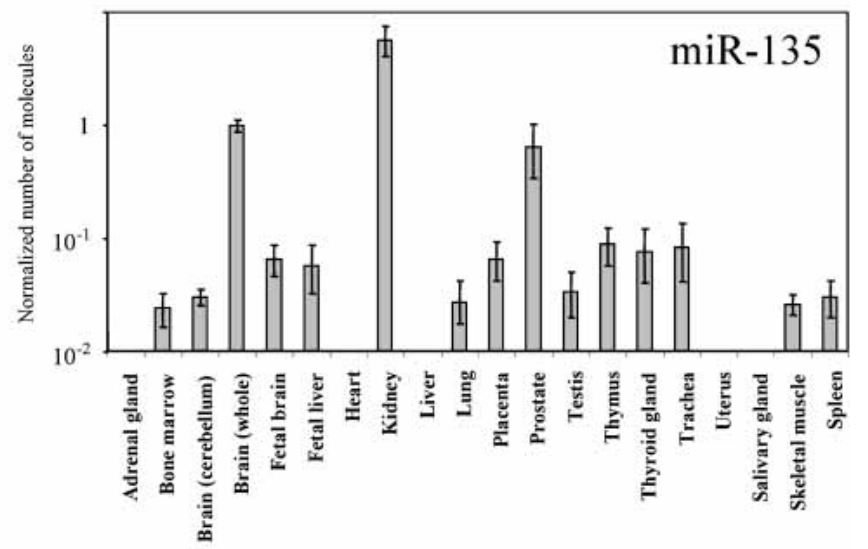

FIGURE 3. Expression profiles for let-7a $(A)$, miR-15 (B), miR-16 (C), miR-125b $(D)$ and miR-135 (E) in 50-100 ng of total RNA from a variety of human tissues. Relative miRNA levels were quantitated using the fluorescence signals generated by the appropriate Invader miRNA assay, adjusted for the amount (in nanograms) of total RNA in each sample. For comparison between samples, these numbers were then normalized to the signal obtained for miRNA in whole brain.

cell contains about 35 pg RNA, the number of let-7a RNA molecules per cell ranged from $\sim 100$ to $\sim 20,000$, depending on the tissue.

Four additional Invader miRNA assays were developed to validate the generality of the detection method. Each In- vader miRNA assay was able to detect its targeted miRNA in a tissue-specific (Fig. 3B-E) and dose-dependent (not shown) manner. As with let-7a RNA, each miRNA had its own tissue-specific differential pattern of expression.

We also tested whether the assay could quantify miRNAs 
TABLE 2. Recovery of miR-1 microRNA in total RNA preparations and cell lysis

\begin{tabular}{lccc}
\hline Cell line & $\begin{array}{c}\text { Attomoles } \\
\text { added }\end{array}$ & $\begin{array}{c}\text { Attomoles } \\
\text { recovered }\end{array}$ & \% recovery \\
\hline $\begin{array}{l}\text { Total RNA preparations } \\
\quad \text { HeLa }\end{array}$ & 2.80 & 1.84 & $66 \%$ \\
$\quad \begin{array}{lll}\text { Hs 578T } \\
\text { Cell lysis }\end{array}$ & 2.80 & 1.83 & $65 \%$ \\
$\quad$ HeLa & & & \\
$\quad$ Hs 578T & 2.80 & 1.84 & $66 \%$ \\
\hline
\end{tabular}

Synthetic drosophila miR-1 (2.8 amoles) was added to $\sim 10^{6}$ HeLa or Hs 578T cells prior to preparation of either NP-40 cell lysates or total RNA samples. Net fluorescence signals generated in the miR-1 Invader miRNA assay were used to calculate attomoles of RNA, using a dose-response curve generated with pure, synthetic miR-1 RNA (data not shown). Similar signal recoveries were observed using other amounts of added miR-1 (data not shown).

in cell lysates, thereby avoiding the need to isolate RNA. To do this, we added synthetic Drosophila melanogaster miR-1 RNA to HeLa or Hs 578T cells and then either prepared cell lysates by treatment with $\mathrm{NP}-40$ at $80^{\circ} \mathrm{C}$ or isolated total RNA by phenol-chloroform extraction (see Materials and Methods). Approximately 70\% of the added signal was detected when assayed in either a total RNA sample or cell lysate (Table 2). In neither case was a signal observed in the absence of added Drosophila miR-1 RNA (data not shown). The percent recovery is likely to vary between samples, because of losses encountered during the extra handling of the RNAs. Thus, the Invader miRNA assay can be reliably per- formed in NP-40 lysates of cells, without RNA isolation and purification.

The stability of let-7a RNA in cell lysates was tested by varying the time of the primary reaction while keeping the secondary reaction time constant. Under these conditions, the net signal produced was proportional to the time of the primary reaction, as would be expected if target RNAs were stable during the assay period (data not shown). A similar stability of GAPDH mRNA was also observed. Treatment of cell lysates with $10 \mathrm{ng} / \mu \mathrm{L}$ RNase A at $37^{\circ} \mathrm{C}$ for $1 \mathrm{~h}$ completely destroyed the generation of signal for both miRNA and mRNA (not shown), indicating that the Invader assay detected the targeted RNAs and not genomic DNA present in lysates.

The results of the Invader miRNA assay are obtained as fluorescence units, normalized to a fixed amount of RNA or number of cells. These numbers are an indicator of the relative amounts of a particular miRNA in an RNA preparation. To calculate the absolute number of miRNA per cell, the relative fluorescence signals per nanogram of total cell RNA were compared to standard curves generated by known amounts of the synthetic miRNA (Fig. 2B), assuming that $\sim 35$ pg RNA can be recovered from each HeLa cell. When this analysis was applied to the let-7a and miR-16 RNAs in total RNA isolated from HeLa cells, we calculated that each cell contained an average of about 4200 molecules of let-7a RNA and about 1300 molecules of miR-16 RNA (Fig. 4). Northern blot analysis of the same HeLa cell RNA preparation indicated that the cells had about 2100 molecules of let-7a RNA and 1700 molecules of miR-16RNA let-7a

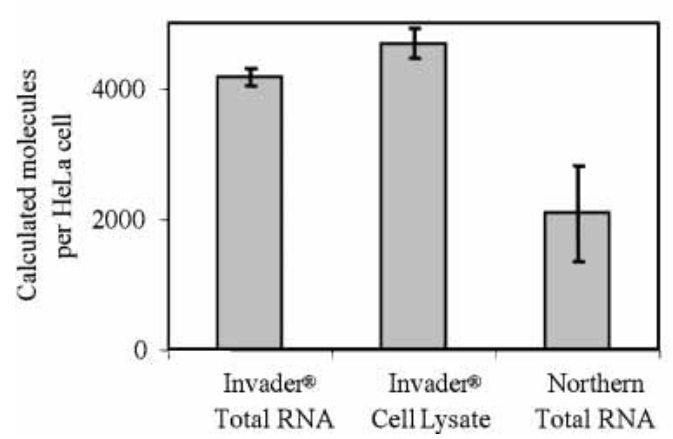

\section{miR-16}

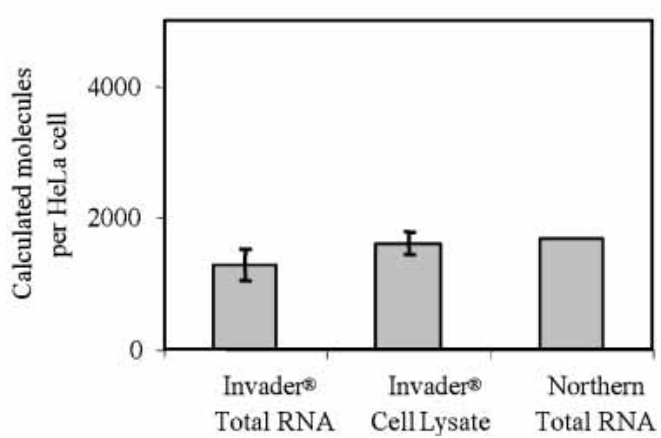

FIGURE 4. Quantities of let-7a and miR-16 RNAs per HeLa cell. Total RNA was isolated from HeLa cells and analyzed either by the Invader let-7a assay or by quantitative Northern blotting. We used $50 \mathrm{ng}$ of RNA in the Invader reaction and the fluorescence signal generated was compared to a standard curve generated using known amounts of synthetic let-7a RNA, to determine attomoles of miRNA per nanogram of HeLa cell RNA. These numbers were converted to molecules per cell, assuming 35 pg RNA per HeLa cell. Standard errors are from the standard curve and three independent measurements. Similarly, the numbers of molecules per cell were calculated when the cells were lysed with NP-40, without RNA isolation. In this case, a total of 4500 cells (counted prior to harvesting) were used in each assay. The Northern blots were performed on 2 or 10 $\mu \mathrm{g}$ of the same HeLa cell RNA preparation used in the Invader assay, with standards of 2.5, 0.50, or 0.25 fmoles of synthetic let-7a RNA and 4.4, 0.44 , or 0.22 fmoles of synthetic miR-16 RNA run on adjacent lanes to generate a standard curve (Lim et al. 2003). The blot was probed with ${ }^{32} \mathrm{P}$-UTP-labeled T7 transcribed RNAs complementary to let-7a or miR-16 RNAs, and signals were quantified on a phosphorimager and were normalized to a standard curve to yield molecules per cell. Standard errors for let-7a Northern blots are the standard deviations of duplicate experiments. A single Northern blot experiment was performed for miR-16; thus no standard errors are reported. The amounts of RNA used as standards were calculated assuming extinction coefficients of 2.38 and $2.26 \times 10^{5} \mathrm{~L} / \mathrm{mole} \cdot \mathrm{cm}$ for let-7a and miR-16 RNAs, respectively. 
(Fig. 4). The data reported by Lim et al. (2003) appear to put the number of let-7a and miR-16 RNAs at about 1400 and 1200 molecules, respectively, but it is unclear what these workers assumed for the amount of RNA per HeLa cell. Similar calculations performed on miRNAs in HeLa cell lysates, rather than isolated RNAs, indicated that each cell contained $\sim 4700$ and $\sim 1600$ copies of let-7a and miR-16 RNA, respectively.

The calculated numbers of miRNAs per cell presented in Figure 4 are within a factor of two of each other, even though two very different types of assays were involved, using considerably different amounts of RNA ( 50 ng vs. $\sim 5-10 \mu \mathrm{g}$ ). Slight differences may result from compounds in the cell RNA preparations that could inhibit or stimulate either the Invader reaction or from inaccuracies in the generation of standard curves. Also, the great specificity of the Invader miRNA assay (Fig. 2) might cause variant miRNA molecules to go undetected, even though they would contribute to the overall signal in a Northern blot. Both the

A

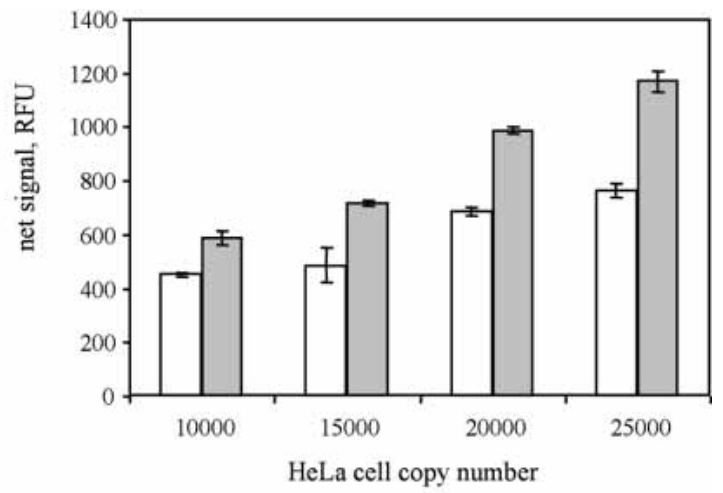

B

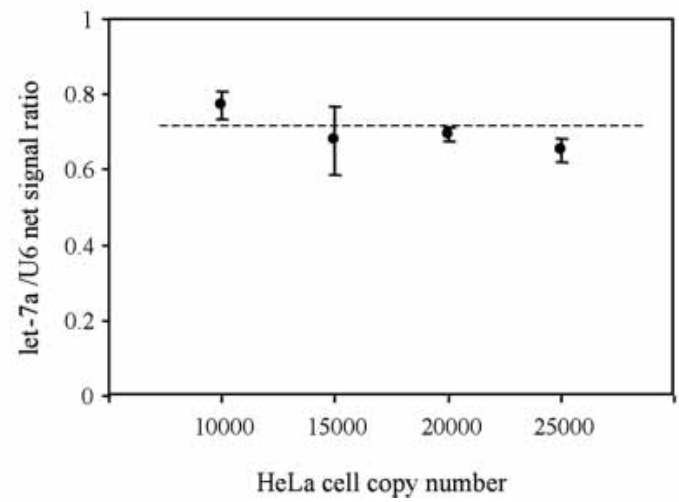

FIGURE 5. Uniform detection of let-7a RNA in HeLa cell lysates, biplexed with a U6 RNA Invader assay for normalization. (A) Net signals for let-7a RNA (open bars) and U6 RNA (gray bars) were measured by a biplex Invader assay of NP-40 performed on lysates of different numbers of HeLa cells. The signals detected for the miRNA and the U6 RNA were from spectrally distinct FAM and Redmond Red fluorophores, respectively. $(B)$ The let-7a net signal values were divided by the corresponding U6 RNA signal values to obtain a normalized signal. The average of the four normalized let-7a values is shown by the dashed line.
Invader miRNA assay and Northern blotting require that assumptions be made about the amount of total RNA per cell and the extent of losses during sample preparation or cell lysis.

The amounts of a miRNA in two different preparations can be compared directly, using another, "housekeeping," RNA as an internal standard. Two different RNAs can be assayed simultaneously by performing the Invader assay in a biplex format, in which the probe oligonucleotide for each RNA has a unique $5^{\prime}$ flap that can be detected in the secondary reaction (Eis et al. 2001; Lund et al. 2003; Wagner et al. 2003). An example of such normalization is demonstrated in Figure 5. Four samples containing different numbers of HeLa cells were lysed by NP-40 treatment at $80^{\circ} \mathrm{C}$, and the lysates were analyzed with a biplex Invader assay designed to detect the let-7a specific signal (FAM fluorescence) and a U6 RNA specific signal (spectrally distinct Redmond Red fluorescence). The levels of both signals were proportional to the amounts of HeLa cells analyzed (Fig. $5 \mathrm{~A})$, so the normalized amount of let-7a signal remained nearly constant across all samples (Fig. 5B). Thus the signal of an unrelated RNA such as U6 can serve for normalization of the let-7a RNA-specific signals in two preparations when the absolute number of cells is unknown. Likewise, the level of let-7a specific signal remained constant when normalized to GAPDH mRNA (data not shown).

The Invader miRNA assay described here presents many advantages not seen with other methods currently in use. It is quantitative, specific, and sensitive (detecting as few as 20,000 miRNA molecules). Also, it is simple, rapid (requiring only $2-3 \mathrm{~h}$ incubation), does not use radioactivity, and is readily performed directly in cell lysates. Accordingly, it lends itself well to applications in high throughput screening. Costs are reduced by purifying probe oligonucleotides in-house by gel electrophoresis, and by the use of a standard secondary reaction so that the same FRET pair oligonucleotide is used in all reactions.

\section{MATERIALS AND METHODS}

\section{Oligonucleotide synthesis and purification}

DNA oligonucleotides were synthesized with an Expedite 8909 synthesizer (PerSeptive Biosystems) using standard phosphoramidite chemistry. All phosphoramidites, including 2'-O-methyl phosphoramidites, were purchased from Glen Research. Synthesis and deprotection were performed according to the manufacturer's procedures. RNA oligonucleotides were purchased from Dharmacon Research Inc. and were deprotected and desalted according to the manufacturer's procedures. All DNA and RNA oligonucleotides used in this study (Table 1) were purified by electrophoresis in a $20 \%$ denaturing acrylamide gel as described (Kaiser et al. 1999). FRET and secondary reaction template (SRT) oligonucleotides were purified as described (Eis et al. 2001). Oligonucleotide concentrations were determined from the absorption at $260 \mathrm{~nm}$ 
using extinction coefficients for nucleosides and dinucleoside monophosphates (Cantor et al. 1970).

\section{Oligonucleotide design for the Invader miRNA assay}

The probe and invasive oligonucleotides required for the primary reaction of the Invader miRNA assay were designed to base pair to equal halves of the miRNA of interest (i.e., for a 22-mer miRNA, both the probe and invasive oligonucleotides formed 11 base pair duplexes with the miRNA). For miRNAs with an odd number of nucleotides, the miRNA region complementary to the probe was 1 nt longer than the region complementary to the invasive oligonucleotide. The only exception to this rule was the design for 24-nt AU-rich (71\% AU) miR-135. For this miRNA, oligonucleotides with $11,12,13$, and $14 \mathrm{nt}$ of complementarity to the miRNA were tested and the design with a 14-nt probe region was found to be optimal.

In all Invader miRNA assays the invasive and probe deoxyoligonucleotides were modified to include 2'-O-methylated stemloops at their $5^{\prime}$ and $3^{\prime}$ ends, respectively, to stabilize hybrids containing the target RNA stacked between the two short base-pair duplexes (Fig. 1C). The 2'-O-methylated stem-loop sequences used in most assays for both the probe and invasive oligonucleotides are listed in Table 1. The invasive oligonucleotide had a $3^{\prime}$ terminal overlapping nucleotide that was not complementary to the miRNA sequence. The probe oligonucleotide had a $5^{\prime}$ flap sequence 5'-AACGAGGCGCAC that, when cleaved from the probe in the primary reaction, is used in the secondary reaction (Fig. 1B). When the $5^{\prime}$ flap sequence would be partially complementary to the miRNA sequence, thereby extending the length of the probe-miRNA heteroduplex, an alternative $5^{\prime}$ flap sequence (5'-CCGTCGCTGCGT) was used (see Table 1).

\section{Cell lysis and RNA preparation}

HeLa and Hs 578T cells (obtained from ATCC, catalog numbers CCL-2 and HTB-126, respectively) were grown in Eagles MEM, Earle's salts (lacking $\mathrm{Ca}^{++}$), supplemented with $10 \%$ fetal calf serum, nonessential amino acids, and Pluronic F68. They were counted with a hemocytometer. Approximately $1 \times 10^{6}$ suspended cells were pelleted by centrifugation at $1000 \mathrm{~g}$ for $3 \mathrm{~min}$, washed once with $1 \mathrm{~mL}$ PBS (no $\mathrm{MgCl}_{2}$, no $\mathrm{CaCl}_{2}$; Invitrogen), and spun down at $1000 \mathrm{~g}$ for $3 \mathrm{~min}$. The cell pellets were suspended in $100 \mu \mathrm{L}$ of $10 \mathrm{mM}$ MOPS ( $\mathrm{pH} 7.5$ ), $100 \mathrm{mM} \mathrm{KCl}$, and $2-\mu \mathrm{L}$ cell aliquots were removed and diluted with $98 \mu \mathrm{L}$ of the lysis buffer containing $20 \mathrm{mM}$ Tris- $\mathrm{HCl}$ (pH 8.5) 0.5\% NP-40, $20 \mu \mathrm{g} / \mathrm{mL}$ tRNA (again, in the absence of added divalent cations), and heated for $15 \mathrm{~min}$ at $80^{\circ} \mathrm{C}$ and centrifuged at $1000 \mathrm{~g}$ for $3 \mathrm{~min}$ to remove debris. Samples of total RNA from HeLa and Hs 578T cells were prepared using TRIZOL reagent (Invitrogen) according to the manufacturer's procedures. RNA concentration was determined from the absorption at $260 \mathrm{~nm}$ (assuming that $1 \mathrm{~A}_{260}=40 \mu \mathrm{g} / \mathrm{mL}$ ). Samples of total RNA from human tissues were purchased from Clontech. The precursor form of let-7a was prepared using standard T7 transcription (Lund et al. 2003).

\section{Invader miRNA assay}

Invader reactions were performed in triplicate in 96-well microplates (MJ Research, Inc.) using an Invader miRNA assay generic reagent kit (\#91-287; Third Wave Technologies, Inc.). To determine optimal temperature of the primary reaction, Invader reactions were performed using 250-amole synthetic miRNA in a heated-lid gradient thermal cycler over a temperature range of $40^{\circ} \mathrm{C}-60^{\circ} \mathrm{C}$ for $30 \mathrm{~min}$, in $10-\mu \mathrm{L}$ volumes containing 10 pmole of each of the probe and invasive oligonucleotides. For no-target controls, $10 \mathrm{ng} / \mu \mathrm{L}$ yeast tRNA (Sigma) was substituted for samples or synthetic miRNA. To prevent evaporation, $10 \mu \mathrm{L}$ of clear ChillOut 14 liquid wax (MJ Research, Inc.) were added to each reaction.

Upon the completion of the primary reaction, $5 \mu \mathrm{L}$ of a secondary reaction mixture including a FAM detection oligonucleotide (\#91-288; Third Wave Technologies, Inc.) and 40 pmole arrestor oligonucleotide were added to the primary reaction. The secondary reaction was performed for $15 \mathrm{~min}$ at $60^{\circ} \mathrm{C}$ and the fluorescence signal detected using a CytoFluor 4000 fluorescence plate reader (Applied Biosystems) using 485/20 nm excitation and $530 / 25 \mathrm{~nm}$ emission filters for the FAM dye. The net fluorescence signal was determined by subtracting the no-target signal from the miRNA sample signal. The optimal reaction temperature was defined as the temperature at which the highest net signal was observed. To determine the miRNA level in a sample, $5 \mu \mathrm{L}$ aliquots of cell lysates or 50-100 ng of total RNA (in $5 \mu \mathrm{L}$ ) were used in the $10-\mu \mathrm{L}$ primary reaction. The primary reaction was performed at the optimal temperature determined for each miRNA for 60 to 90 min and the secondary reaction was performed at $60^{\circ} \mathrm{C}$ for 60 to 90 min. Five-microliter samples of synthetic miRNA with known concentrations in the range $5 \mathrm{fM}-5 \mathrm{pM}$ ( 25 zmole-25 amole) were used in the Invader assay to obtain a dose response curve for miRNA quantitation in total RNA or cell lysate samples.

For biplex Invader miRNA assays, Invader GAPDH mRNA and U6 RNA kits (\#94-002; Third Wave Technologies, Inc.) were used (Table 1), and their Redmond Red dye (Epoch Biosciences) signals were detected using 560/20 $\mathrm{nm}$ excitation and 620/40 $\mathrm{nm}$ emission filters.

\section{Data analysis}

Data were analyzed as described previously (Eis et al. 2001) using Microsoft Excel 97 (Microsoft). Error propagation and analysis were performed using standard error propagation methods (Bevington 1969).

\section{ACKNOWLEDGMENTS}

We thank Laura Heisler and Peggy Eis for critical reading of the manuscript. J.E.D. and E.L. are supported in part by National Institutes of Health grant R37-GM30220 and have financial interests in Third Wave Technologies.

The publication costs of this article were defrayed in part by payment of page charges. This article must therefore be hereby marked "advertisement" in accordance with 18 USC section 1734 solely to indicate this fact.

Received December 1, 2003; accepted March 23, 2004.

\section{REFERENCES}

Banerjee, D. and Slack, F. 2002. Control of developmental timing by small temporal RNAs: A paradigm for RNA-mediated regulation of gene expression. Bioessays 24: 119-129. 
Bartel, D.P. 2004. MicroRNAs: Genomics, biogenesis, mechanism, and function. Cell 116: 281-297.

Bevington, P.R. 1969. Propagation of errors. In Data reduction and error analysis for the physical sciences, pp. 56-60. McGraw-Hill Book Company, New York.

Cantor, C.R., Warshaw, M.M., and Shapiro, H. 1970. Oligonucleotide interactions. III. Circular dichroism studies of the conformation of deoxyoligonucleotides. Biopolymers 9: 1059-1077.

Carmell, M.A., Xuan, Z., Zhang, M.Q., and Hannon, G.J. 2002. The Argonaute family: Tentacles that reach into RNAi, developmental control, stem cell maintenance, and tumorigenesis. Genes \& Dev. 16: $2733-2742$.

Carrington, J.C. and Ambros, V. 2003. Role of microRNAs in plant and animal development. Science 301: 336-338.

de Arruda, M., Lyamichev, V.I., Eis, P.S., Iszczyszyn, W., Kwiatkowski, R.W., Law, S.M., Olson, M.C., and Rasmussen, E.B. 2002. Invader technology for DNA and RNA analysis: Principles and applications. Expert Rev. Mol. Diagn. 2: 487-496.

Dykxhoorn, D.M., Novina, C.D., and Sharp, P.A. 2003. Killing the messenger: Short RNAs that silence gene expression. Nat. Rev. Mol. Cell. Biol. 4: 457-467.

Eis, P.S., Olson, M.C., Takova, T., Curtis, M.L., Olson, S.M., Vener, T.I., Ip, H.S., Vedvik, K.L., Bartholomay, C.T., Allawi, H.T., et al. 2001. An invasive cleavage assay for direct quantitation of specific RNAs. Nat. Biotechnol. 19: 673-676.

Hall, J.G., Eis, P.S., Law, S.M., Reynaldo, L.P., Prudent, J.R., Marshall, D.J., Allawi, H.T., Mast, A.L., Dahlberg, J.E., Kwiatkowski, R.W., et al. 2000. Sensitive detection of DNA polymorphisms by the serial invasive signal amplification reaction. Proc. Natl. Acad. Sci. 97: 8272-8277.

Kaiser, M.W., Lyamicheva, N., Ma, W., Miller, C., Neri, B., Fors, L., and Lyamichev, V.I. 1999. A comparison of eubacterial and archaeal structure-specific 5'-exonucleases. J. Biol. Chem. 274: 21387-21394.

Kidner, C.A. and Martienssen, R.A. 2003. Macro effects of microRNAs in plants. Trends Genet. 19: 13-16.

Kim, J., Krichevsky, A., Grad, Y., Hayes, G.D., Kosik, K.S., Church, G.M., and Ruvkun, G. 2004. Identification of many microRNAs that copurify with polyribosomes in mammalian neurons. Proc. Natl. Acad. Sci. 101: 360-365.

Krichevsky, A.M., King, K.S., Donahue, C.P., Khrapko, K., and Kosik, K.S. 2003. A microRNA array reveals extensive regulation of microRNAs during brain development. RNA 9: 1274-1281.

Lagos-Quintana, M., Rauhut, R., Lendeckel, W., and Tuschl, T. 2001. Identification of novel genes coding for small expressed RNAs. Science 294: 853-858.
Lau, N.C., Lim, L.P., Weinstein, E.G., and Bartel, D.P. 2001. An abundant class of tiny RNAs with probable regulatory roles in Caenorhabditis elegans. Science 294: 858-862.

Lee, R.C. and Ambros, V. 2001. An extensive class of small RNAs in Caenorhabditis elegans. Science 294: 862-864.

Lee, R.C., Feinbaum, R.L., and Ambros, V. 1993. The C. elegans heterochronic gene lin- 4 encodes small RNAs with antisense complementarity to lin-14. Cell 75: 843-854.

Lim, L.P., Lau, N.C., Weinstein, E.G., Abdelhakim, A., Yekta, S., Rhoades, M.W., Burge, C.B., and Bartel, D.P. 2003. The microRNAs of Caenorhabditis elegans. Genes \& Dev. 17: 991-1008.

Lund, E., Guttinger, S., Calado, A., Dahlberg, J.E., and Kutay, U. 2003. Nuclear export of microRNA precursors. Science. 303: 95-98.

Lyamichev, V., Mast, A.L., Hall, J.G., Prudent, J.R., Kaiser, M.W., Takova, T., Kwiatkowski, R.W., Sander, T.J., de Arruda, M., Arco, D.A., et al. 1999. Polymorphism identification and quantitative detection of genomic DNA by invasive cleavage of oligonucleotide probes. Nat. Biotechnol. 17: 292-296.

Lyamichev, V.I., Kaiser, M.W., Lyamicheva, N.E., Vologodskii, A.V., Hall, J.G., Ma, W.P., Allawi, H.T., and Neri, B.P. 2000. Experimental and theoretical analysis of the invasive signal amplification reaction. Biochemistry 39: 9523-9532.

Moss, E.G. and Poethig, R.S. 2002. MicroRNAs: Something new under the sun. Curr. Biol. 12: R688-R690.

Mourelatos, Z., Dostie, J., Paushkin, S., Sharma, A., Charroux, B., Abel, L., Rappsilber, J., Mann, M., and Dreyfuss, G. 2002. miRNPs: A novel class of ribonucleoproteins containing numerous microRNAs. Genes \& Dev. 16: 720-728.

Pasquinelli, A.E. and Ruvkun, G. 2002. Control of developmental timing by micrornas and their targets. Annu. Rev. Cell. Dev. Biol. 18: 495-513.

Pasquinelli, A.E., Reinhart, B.J., Slack, F., Martindale, M.Q., Kuroda, M.I., Maller, B., Hayward, D.C., Ball, E.E., Degnan, B., Muller, P., et al. 2000. Conservation of the sequence and temporal expression of let-7 heterochronic regulatory RNA. Nature 408: 86-89.

Reinhart, B.J., Weinstein, E.G., Rhoades, M.W., Bartel, B., and Bartel, D.P. 2002. MicroRNAs in plants. Genes \& Dev. 16: 1616-1626.

Sempere, L.S., Freemantle, S., Pitha-Rowe, I., Moss, E., Dmitrovsky, E., and Ambros, V. 2004. Expression profiling of mammalian microRNAs uncovers a subset of brain-expressed microRNAs with possible roles in murine and human neuronal differentiation. $\mathrm{Ge}$ nome Biol. 5: R13.

Wagner, E.J., Curtis, M.L., Robson, N.D., Baraniak, A.P., Eis, P.S., and Garcia-Blanco, M.A. 2003. Quantification of alternatively spliced FGFR2 RNAs using the RNA invasive cleavage assay. RNA 9: 15521561. 

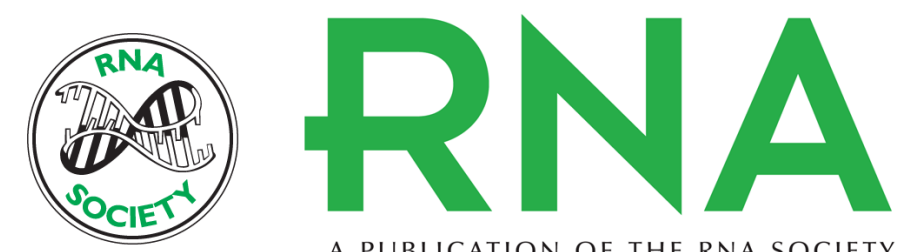

A PUBLICATION OF THE RNA SOCIETY

\section{Quantitation of microRNAs using a modified Invader assay}

HATIM T. ALLAWI, JAMES E. DAHLBERG, SARAH OLSON, et al.

RNA 2004 10: 1153-1161

References This article cites 27 articles, 13 of which can be accessed free at: http://rnajournal.cshlp.org/content/10/7/1153.full.html\#ref-list-1

\section{License}

Email Alerting Receive free email alerts when new articles cite this article - sign up in the box at the top Service right corner of the article or click here. 